\title{
DOCUMENTOS
}

\section{LAS PINTURAS DEL EXCOLEGIO DE TEPOTZOTLÁN}

\section{Clemmentina díaz y de Ovando}

Este año de 1984 se cumple y se celebra el tercer centenario de la dedi. cación del templo de San Francisco Javier (Tepotzotlán). En mis investigaciones en la Hemeroteca Nacional he encontrado en la prensa periódica de fines del siglo $\mathrm{xrx}$, varias noticias acerca del exconvento de Tepotzotlán que me parece pertinente transcribir ya que pueden ser de alguna utilidad para la historia del exconvento jesuita.

Una de ellas se refiere al absurdo destino que se pretendía dar al edificio: convertirlo en penitenciaría. Proyecto que, al decir de Francisco de la Maza, renació durante el porfirismo. ${ }^{1}$ Otras noticias se refieren a la denuncia y requerimiento que los más importantes diarios de la capital de la República hicieron ante el Ministerio de Gobernación sobre el despojo de las pinturas que estaban en el claustro del exconvento de Tepotzotlán, y que muestran el interés de la prensa en la salvaguarda del patrimonio artístico nacional siempre desprotegido y a merced de la incultura o de la incuria. La interpelación de los periódicos al ministro fue atendida y se dictaron las órdenes para el esclarecimiento de la. "extracción" de las pinturas. La prensa dio a conocer los acuerdos del ministro y el del presidente de la República quien decidió que las pinturas quedaran a disposición de la "autoridad política del distrito de Cuautitlán". En los oficios figura el inventario de la entrega del exconvento de Tepotzotlán que da idea de como se encontraba el edificio en la década de los años ochenta. La prensa también hizo público el traslado de la biblioteca de los jesuitas de Tepotzotlán a la capital del Estado de México, Toluca.

\section{DOCUMENTOS}

PENITENCIARÍA En el exconvento de Tepotzotlán, cedido por el gobierno de la Unión al Estado de México, se va a construir una. Está

1 Discurso de Francisco de la Maza pronunciado el 19 de septiembre de 1964 con motivo de la inauguración del Musẹo Nacional del Viryeinato, en Politica, Méxido, 1 de octubre de 1964. 
encargado de la obra el C. Ramón de Arangoity, quien parece comprometerse a terminarla antes de seis años, comenzando los trabajos el $1^{\circ}$ de enero de 1872.

El Monitor Republicano, 14 de noviembre de 1871.

¿A DÓNDE FUERON A DAR? En uno de los curatos que antiguamente eran conventos de frailes, se presentó últimámente un individuo con una orden del gobierno para recoger toda la colección de pinturas que había en dicho convento, y fueron entregadas.

Esos cuadros estaban en los claustros, se consideraban como bienes nacionales. ¿Podrá decirnos el Diario, a dónde fueron a parar?

¿En caso de negativa podrá $L a$ Voz, decirnos, qué sabe de estor.Un suscritor.

El Republicano, 15 de diciembre de 1880.

¿A DÓNDE FUERON A DAR? - Nada habíamos contestado hasta hoy, porque ignorábamos el hecho a que se refiere nuestro colega $[E l$ Republicano], y porque esperábamos además, que habláse antes el Diario Oficial, a quien interpelaba primero El Republicano. Pero puesto que el colega de Palacio guarda silencio, y que ya hemos adquirido algunos informes sobre el caso, diremos lo que a nuestras noticias ha llegado.

El curato de que se trata es Tepotzotlán, y se nos informa que efectivamente de sus claustros han sido recogidas hace poco, por orden superior (ignoramos quien la dió) cerca de trescientas pinturas, en su mayor parte de gran mérito artístico. Hasta aquí nuestros informes. Suponemos pues que el hecho de que se trata fue motivado por orden de autoridad competente, tales pinturas servirán para enriquecer la colección de la Academia de San Carlos, conservando al mismo tiempo con el debido esmeto esas obras de valía y de estima en todas las naciones cultas. Toca al Diario Oficial confirmar o ratificar los informes que nos han dado, $e$ indicar el destino final de las referidas pinturas.

Es extraño que se hayan podido extraer de un edificio público, un número tan grande de pinturas, sin haber llamado la atención pública.

La Voz de México, 18 de diciembre de 1880. 
EL NACIONAL recomienda que se trasladen a lugar más conveniente algunas pinturas antiguas que se conservan en el excolegio de Tepotzotlán.

El Monitor Republicano, 19 de diciembre de 1880.

CUADROS.-Con motivo de haber publicado El Republicano un párrafo en que se decía que un individuo se había sacado de uno de los curatos que antiguamente fueran conventos, una colección de pinturas, cuyo paradero se ignoraba, dice El Nacional lo siguiente refiriéndose al Sr. Diéz Gutiérrez.

"El ministro ha mandado practicar una averiguación minuciosa respecto de este hecho, y en lo que resulte, se procederá con toda justicia dando cuenta a la prensa de lo que se determine." *

\section{El Monitor Republicano, 21 de diciembre de 1880.}

HAX GRAN EXCITACIÓN en Tepotzotlán a causa del despojo de pinturas que se quiere hacer en el antiguo colegio de jesuítas. Dicen los vecinos que siendo los cuadros propiedad del edificio en la población, deben quedarse alli. Nosotros creemos que, sin embargo, que siendo el edificio propiedad de la nación puede el gobierno disponer de sus pinturas adonde sean más útiles y puedan lucir más.

Sabemos que los principales cuadros se deben al pincel de Juan de Villalpando, pintor que ha popularizado José Peón Contreras, haciéndolo protagonista de uno de sus más bellos dramas. ***

El ministro de Gobernación ha dictado, según dice un colega [El Monitor Republicano], las órdenes necesarias para averiguar si es cierto que existen libros antiguos y cuadros notables, en el Colegio de Tepotzotlán, y en la biblioteca del Carmen del Desierto, en cuyo caso se tomarán las medidas necesarias, para que uno y otros queden a disposición del gobierno.

Esta vez, como siempre, el señor Diéz Gutiérxez ha escuchado las indicaciones de la prensa.

La Voz de España, 23 de diciembre de 1880.

* El Nacional del año 1880 no se encuentıa en la Hemeroteca Nacional y, por lo mismo, no pude consultarlo.

** Seguramente se trata del pintor Cristóbal de Villalpando quien pintó para Tepotzotlán una serie de cuadros sobre la vida de San Ignacio de Loyola. 
LAS PINTURAS DEL EXCONVENTO DE TEPOTZOTLAN.-La prensa toda se ocupó en días pasados de interpelar a la Secretaría de Gobernación, respecto de la extracción de las pinturas que existian en el exconvento de Tepotzotlán.

El señor Ministro de Gobernación dictó descle luego todas las órdenes necesarias para el esclarecimiento de los hechos.

He aquí los documentos relativos:

"Acuerdo del Secretario de Gobernación.-núm. 150, Marzo.-Diciembre, libro 20 fojas 453.-Sección 2a.-México, Diciembre 20 de 1880.226 legajo fojas 176.

Dígase al depositario del exconvento de Tepotzotlán, informe si existen en ese edificio algunos cuadros que decoraban sus tránsitos; y en caso negativo inquiera con la mayor diligencia su paradero, y logrado que sea los asegure, dando cuenta a esta Secretaría para que determine lo conveniente, pidiendo auxilio a la fuerza rural destacada en Cuautitlán, si lo creyere conveniente para el desempeño de esta comisión. Funden este oficio en las noticias que ha recibido la Secretaria, relativas a haberse extraído dichas pinturas, cuya noticia está confirmada con las aseveraciones de la prensa, especialmente por lo publicado a este respecto en el Nacional de antier y el Republicano de ayer. Librese la orden al jefe de la fuerza en Cuautitlán.

Secretaría de Estado y del Despacho de Gobernación-México--Sección 2a.

Ha tenido noticia el Gobierno por varios conductos, de que últimamente fueron extraídos del exconvento de Tepotzotlán varios cuadros de pintura y algunos otros objetos; como dicha noticia ha sido reproducida por la prensa de esta capital, dispone el Presidente de la República informe usted a esta Secretaría a la posible brevedad, sobre si es cierto el hecho referido, o existen aún en aquel edificio los mencionados cuadros; en este segundo caso los conservará usted a disposición de esta Secretaría, mas si hubiesen sido extraidas dichas pinturas como se dice, procederá usted con la mayor diligencia a averiguar su paradero, y una vez logrado, cualquiera que sea el lugar en que se encuentren las asegurará usted; pidiendo al efecto auxilio, si 'necesario fuere, a la fuerza rural que existe en Cuautitlán, y dando cuenta inmediatamente a este Ministerio.

Espera el Presidente, desempeñará usted esta comisión con la energía y prudencia que el caso requiere. 
Libertad en la Constitución. México, Diciembre 20 de 1880.-Diéz Gutiérrez.

Al depositario del exconvento de Tepotzotlán.-Presente.

Se ha encomendado al ciudadano Carlos Zimmermann, depositario del exconvento de Tepotzotlán, el desempeño de una comisión del servicio público, a cuyo efecto dispone el Presidente se sirva usted prestar al expresado ciudadano el auxilio que le pidiere.

Libertad en la Constitución. México, Diciembre 20 de 1880-Diéz Gutiérrez,-Al jefe de la fuerza rural destacada en Cuautitlán.

Al margen.-Recibo del inventario; y enterado del informe que rinde sobre el paradero de las pinturas de que se trata; y que en vista de lo expuesto por el Jefe Político, cuyas aseveraciones sobre el particular están corroboradas con lo que manifiesta a esta Secretaría el Gobernador del Estado con fecha 22 del actual, deje a disposición de la expresada autoridad política, los cuadros a que se refiere, recogiendo las bancas que menciona y reservándolas a la orden de esta Secretaría.

Ha sido en mi poder la comunicación de usted fecha 2 del actual relativa a que averigüe el paradero de las pinturas que existían en este convento de Tepotzotlán, y comprendiendo que la autoridad municipal de este lugar podría con mejores datos esclarecerme este negocio, ocurrí inmediatamente al Presidente Municipal, quien me dijo que: las pinturas mencionadas existen en su poder por orden que recibió del Jefe Político del distrito de Cuautitlán, con esa noticia, me trasladé a la cabecera de este Distrito y dirigí a esta autoridad una comunicación exigiéndole me diera la orden respectiva para que por la autoridad municipal de este lugar, me entregara las mencionadas pinturas, transcribiéndole al mismo tiempo la comunicación de ese Ministerio, y en contestación trascribo a usted la comunicación que dicho Jefe Político se sirvió darme en contestación, a mi nota relativa.

"En respuesta a la atenta nota de usted, fecha de hoy, en la que sirve insertar la del Ministerio de Gobernación del día anterior relativa al paradero y existencia de las pinturas del exconvento de Tepotzotlán, debo manifestarle que: dichas pinturas se encuentran depositadas en poder de la autoridad municipal de esa Cabecera por orden que recibió de esta oficina con fecha 23 del pasado en obedecimiento de la superior disposición del Estado, comunicada a la Jefatura de mi cargo, con fecha. 
19 del indicado Noviembre, en la que me previno dicho depósito bajo inventario escrupuloso para resolver lo que corresponda, por cuya causa hoy consulto al mismo Superior Gobierno del Estado, si deben entregarse a usted lo que verificaré desde luego si así me lo previniere."

Por la anterior comunicación verá esa Secretaría que las pinturas existen en poder de autoridad competente, por cuya causa no fue necesario ningún acto de violencia, sino que limitándome a ejercer sólo la sobrevigilancia, previne al Jefe Político que bajo su más estrecha responsabilidad quedaba este depósito sin que pudiera extraer ninguna pieza, mientras el Gobierno de la Unión disponía lo conveniente.

Concluidas estas diligencias me volvi a esta Cabecera con una carta que en lo particular el Jefe Político me dio, para el Presidente Municipal, con el objeto de que me enseñara las pinturas, las cuales, aunque de una manera violenta por no dilatar esta contestación examiné en número de ciento cinco de diversos tamaños todas, y maltratadas la mayor parte de ellas, por la acción del tiempo y el poco cuidado que han tenido en conservarlas.

Advertiré a usted también que en la capilla que fue de los novicios existen algunos objetos manuables y entre ellos seis bancas que por su calidad y construcción me parecen de mérito y que el Jefe Político no creyó conveniente que figuraran en el inventario por el cual me entregó y que en debida forma acompaño a usted esperando sólo su superior determinación en el negocio de que se trata.

Tepotzotlán, Diciembre 22 de 1880--C. Zimmermann, C. Srio. de Gobernación.

Inventario que sirve para la entrega del Exconvento de esta cabecera, que hace el Presidente Municipal, Joaquín Pérez Tejada, al C. Carlos Zimmermann nombrado por el Ministerio de Gobernación para recibirlo, según órdenes del jefe político del Distrito, Ambrosio Molina.

Un cuarto que sirve de entrada, con otro cuarto interior y tiene tres puertas, un claustro de cuatro corredores en los cuales hay doce puertas que dan entrada a la igual número de celdas; en el intermedio hay un patio que tiene comunicación por una puerta que da el mismo claustro, en el cual hay dos aljibes y seis plantas de naranjos, de allí sigue otro claustro que tiene seis celdas y un común, estos claustros reciben la luz así como las celdas por unas ventanas que dan a los patios y cuyas puertas están en mal estado, de allí sigue otra puerta chica que comunica a otro claustro, donde se hallan diez celdas y una capilla la cual 
no tiene más de un colateral dorado, sigue una escalera de mampostería que conduce a un patio, en el piso bajo y se llama los Naranjos, y otra puerta grande que en el nivel del piso natural conduce a otro claustro compuesto de cuatro corredores con catorce celdas y un común; tanto estos claustros como las celdas se proveen de luz por unas ventanas que el primero tiene para el patio de los Naranjos, con puertas en buen estado, así como sus vidrieras y los segundos con ventanas que caen a la huerta, con puertas sin vidrios y verjas sin fierro, a la derecha de la entrada de este claustro está una escalera que conduce a un pasadizo, el cual se comunica con el patio de los Naranjos, en donde hay un corredor de bóveda, en todo el cuadro y siete cuartos con seis puertas y en el patio once plantas de naranjos, así como una fuente en medio de este pasadizo se entra a una pieza bastante grande conocida por el refectorio, de allí sigue un pasadizo que conduce a la cocina donde hay un brasero, de esta sigue un patio en donde hay seis bodegas y una escalera que sube a comunicarse por la puerta para el claustro primero, además tiene otra puerta que conduce a otro patio donde hay cuartos de bóveda, viejos, y donde tanto en el interior como en la bóveda expresados, se ha creado mucha hierba, de éste sigue otro patio chico que conduce a otra puerta que va para una huerta que tendrá de cavidad veinticuatro cuartillos de sembradura de semilla de maíz, cuya huerta está cercada con tapia bastante alta de piedra y mezcla, en dicha huerta se hallan plantados varios árboles de distintas frutas como lo son: olivos, perales, perones, higueras, ahuacates, duraznos y almendros; la mayor parte de estos árboles son ya muy viejos y algunos se están secando, la huerta está en completo estado de abandono, el techo de todos estos claustros y cuartos de que se ha hecho mención son de bóveda y están bien conservados, pero del claustro donde se halla la capilla, sube una escalera de mampostería para los claustros superiores y estos están compuestos de cinco corredores, y diez y ocho celdas, los techos de estas sólo cinco están en regular estado, pues los demás están sostenidos por puntales así como una parte de dos de los corredores, estos claustros y celdas reciben la luz de las ventanas que tienen y caen para los patios, las de los primeros con bastidores de vidrieras y en muy mal estado y las ventanas de las celdas en regular estado; en estos claustros hay común y una puerta que da a un mirador de techo de bóveda y dos puertas que conducen a la azotea.

Tepotzotlán, Diciembre 14 de 1880.-Entregué, Joaquín Pérez Tejada. -Recibí, C. Zimmermann-Vo. Bo., Ambrosio Molina. 
Secretaría de Estado y del despacho de Gobernación.-Sección 2a.

Se recibió en esta Secretaría el inventario con que el Presidente Municipal de Tepotzotlán hizo a usted entrega del exconvento de 'Tepotzotlán; e impuesto del informe que rinde usted sobre el paradero de las. pinturas que fueron extraídas de aquel edificio, le manifiesto, en respuesta: que en vista de lo expuesto por el jefe político del distrito de Cuautitlán, cuyas aseveraciones sobre el particular, están corroboradas con lo que manifiesta a esta Secretaría, el gobernador del Estado de México en oficio fecha 22 del actual, deje usted a disposición de la cxpresada autoridad política los cuadros de que se trata; recogiendo las bancas a que hace usted referencia y conservándolas a disposición de esa secretaría.

Libertad en la Constitución. México, Diciembre 25 de 1880-Diéz Gutiérrez.

Al depositario del exconvento de Tepotzotlán C. Carlos Zimmermann. -Tepotzotlán.

República Mexicana.-Gobierno del Estado libre y soberano de México.-A la sección 2a.-Manifestando que este gobierno cedió el exconvento de Tepotzotlán sin comprender la colección de cuadros y demás muebles.

Diciembre de 1880.-Comuníquese en respuesta lo acordado al oficio. relativo del depositario.-Núm. 150. Marzo--Diciembre, Lic. 20 f. 453.Sección $2 \mathrm{a}$.

Teniendo conocimiento este gobierno de que por la Secretaría del digno cargo de usted se ha dado orden al depositario del exconvento de Tepotzotlán, para que recoja los cuadros de pinturas y algunos otros objetos pertenecientes a dicho exconvento, tengo el honor de manifestar a usted, para conocimiento del Presidente de la República, que el Ejecutivo del Estado, autorizado por la $\mathrm{H}$. Legislatura, hizo cesión del exconvento de que se trata sin comprender las colecciones de cuadros y demás muebles, que deberán ser conducidos a esta capital para uso de los establecimientos públicos del Estado, y como objetos de la propiedad del mismo Estado.

En vista de lo expuesto, el gobierno de mi cargo dictó, con fecha 19 de Noviembre último, las determinaciones respectivas, a efecto de que, previo riguroso inventario fueran depositados los objetos de que se trata. 
Independencia y Libertad. Toluca, Diciembre 22 de 1880.-Marino Zúñiga.

Al Secretario de Estado y del despacho de Gobernación.-México.

Secretaría de Estado y del despacho de Gobernación--México. Sección 2a.

En vista de lo que se sirve usted manifestar en su oficio, fecha 22 del actual, relativamente a las pinturas que fueron extraidas del exconvento de Tepotzotlán, tengo el honor de manifestar a usted, en respuesta, por acuerdo del Presidente, que ya ordena al depositario del expresado edificio, deje dichas pinturas a disposición de la autoridad política del distrito de Cuautitlán.

Libertad en la Constitución. México, Diciembre 25 de 1880. Diéz Gutiérrez.

$\mathrm{Al}$ gobernador del Estado de México.-Toluca. *

La República, 30 de diciembre de 1880.

LA BIBLIOTECA DE TEPOTZOTLÁN.-Según el informe que ha recibido el Ministerio de Gobernación, existía efectivamente en el antiguo convento de jesuitas de esa población el resto de una biblioteca que había sido de aquellos padres. Pero el gobierno del Estado de México que entró por concesión que le otorgó el Gobierno Federal en posesión del expresado convento, se apoderó también de los libros que allí había, trasladándolos a Toluca.

La República, 5 de enero de $188 \mathrm{I}$.

* Estos documentos también los insertó El Nacional el $1^{\circ}$ de enero de 1881 , antecedidos de estas líneas: "Publicamos a continuación las comunicaciones que han mediado en este asunto, en el cual el Secretario de Gobernación ha procedido con su actividad y celo de costumbre. Recordamos que El Nacional fue el primero que llamó la atención del señor Diéz Gutiérrez sobre la existencia de las pinturas de que se trata." 